\title{
Comparison of latest generation supra-annular and intra-annular self-expanding transcatheter heart valves
}

\author{
Costanza Pellegrini ${ }^{1}$, Tobias Rheude ${ }^{1}$, Jonathan Michel ${ }^{1}$, Hector A. Alvarez-Covarrubias ${ }^{1,4}$, \\ Sarah Wünsch ${ }^{1}$, N. Patrick Mayr ${ }^{2}$, Erion Xhepa ${ }^{1}$, Adnan Kastrati ${ }^{1,3}$, Heribert Schunkert ${ }^{1,3}$, \\ Michael Joner ${ }^{1,3}$, Markus Kasel ${ }^{1,5}$
}

${ }^{1}$ Klinik für Herz-und Kreislauferkrankungen, Deutsches Herzzentrum München, Technical University Munich, Munich, Germany; ${ }^{2}$ Institut für Anästhesiologie, Deutsches Herzzentrum München, Technical University Munich, Munich, Germany; ${ }^{3}$ Deutsches Zentrum für Herz-und KreislaufForschung (DZHK) e.V. (German Center for Cardiovascular Research), Partner Site Munich Heart Alliance, Munich, Germany; ${ }^{4}$ Hospital de Cardiología, Centro Médico Nacional Siglo XXI, Instituto Mexicano del Seguro Social, Ciudad de México, México; ${ }^{5}$ Department of Cardiology, University Heart Center Zurich, Zurich, Switzerland

Contributions: (I) Conception and design: All authors; (II) Administrative support: H Schunkert, AM Kasel, M Joner, A Kastrati, E Xhepa; (III) Provision of study materials or patients: J Michel, AM Kasel, M Joner, A Kastrati, HA Alvarez-Covarrubias; (IV) Collection and assembly of data: C Pellegrini, T Rheude, S Wünsch, NP Mayr, J Michel; (V) Data analysis and interpretation: C Pellegrini, T Rheude, S Wünsch, HA AlvarezCovarrubias, NP Mayr, J Michel, E Xhepa; (VI) Manuscript writing: All authors; (VII) Final approval of manuscript: All authors.

Correspondence to: Prof. Dr. med Michael Joner. Klinik für Herz-und Kreislauferkrankungen, Deutsches Herzzentrum München, Munich, Germany. Email: joner@dhm.mhn.de.

Background: This study compares two latest-generation self-expanding transcatheter heart valves (THV), the supra-annular ACURATE neo (Boston Scientific) and the intra-annular Centera THV (Edwards Lifesciences).

Methods: In this single center observational cohort trial 317 patients treated with the ACURATE neo and 78 patients treated with the Centera TVH were included. The main endpoints were device success and the early safety endpoint at 30 days.

Results: Besides higher incidence of diabetes mellitus and higher body mass index in patients treated with the ACURATE neo THV, there were no baseline differences between the groups. Device success was similar in both groups (neo: $91.8 \%$ vs. Centera: $93.6 \%$; $=0.598$ ), with numerically higher rates of moderate to severe paravalvular leakage in the ACURATE neo group (4.7\% vs. $1.3 \% ; \mathrm{P}=0.214)$. At 30 days all-cause mortality rates were low in both groups $(0.3 \%$ vs. $0 \% ; \mathrm{P}=0.620)$ and no difference occurred in the early safety at 30 days $(19.3 \%$ vs. $16.7 \% ; \mathrm{P}=0.599)$. However, all-cause stroke rates were significantly higher in patients treated with the Centera THV (6.4 vs. $1.6 \%$; $=0.015)$.

Conclusions: The ACURATE neo and the Centera THV show low mortality rates as well as comparable, favorable hemodynamics. The finding of higher stroke rates at 30 days with the repositionable Centera SETHV needs further assessment.

Keywords: Transcatheter aortic valve implantation (TAVI); self-expanding (SE); supra-annular; intra-annular; 30 days outcome

Submitted Apr 21, 2020. Accepted for publication Sep 02, 2020.

doi: $10.21037 /$ jtd-20-1700

View this article at: http://dx.doi.org/10.21037/jtd-20-1700

ㄷ Journal of Thoracic Disease. All rights reserved. 


\section{Introduction}

Over the last decades transcatheter aortic valve implantation (TAVI) evolved from a therapeutic technique reserved for otherwise inoperable patients to the standard of care for high- and intermediate-risk patients suffering from severe aortic valve stenosis. Only recently, evidence from prospective randomized clinical trials extended this indication to low-risk $(1,2)$.

With technological advances of transcatheter heart valves (THV), increasing operator experience and use of low-profile delivery systems, procedural outcomes have improved considerably, reducing one-year mortality from $24 \%$ (3) in high-risk patients to $12 \%$ in intermediate riskpatients (4).

While first generation self-expanding (SE) THV have been associated with higher rates of paravalvular leakage (PVL), increased permanent pacemaker implantation (PPI) and more need for multiple valves (5), next generation SETHV substantially mitigated these hazards. For instance, low PPI rates ranging from $2.3 \%$ to $9.9 \%$ have been described with the ACURATE neo SE-THV (Boston Scientific, Marlborough, Massachusetts, USA) $(6,7)$, however at the cost of more than mild PVL rates of $5 \%(8,9)$. Recently, the Centera SE-THV (Edwards Lifesciences, Irvine, California, USA) showed promising initial results with low PPI rates of $4.9 \%$ and very low incidence of more than mild PVL $<1 \%$ (10).

Among a number of important valve components, leaflet mounting within the stented frame relative to the native aortic annulus, i.e., supra-annular or intra-annular design is of extraordinary relevance owing to expected differences in valve hemodynamics and procedural specifications. A supra-annular THV is designed to avoid interference with the native annulus preventing blood flow obstruction, thus leading to lower transvalvular gradients and higher effective orifice areas (EOAs) (11). On the other hand, an intra-annular THV mimics aortic anatomy and bears the potential advantage of less interaction with the coronary arteries, possibly preventing obstruction.

Despite the recent market withdrawal of the Centera SE-THV, we aimed to investigate whether its intraannular design may result in improved outcome with regards to established updated Vascular Academic Research Consortium (VARC-2) endpoints compared with the supraannular design of the ACURATE Neo SE-THV.

We present the following article in accordance with the "Strengthening the Reporting of Observational Studies in
Epidemiology (STROBE) reporting checklist (available at http://dx.doi.org/10.21037/jtd-20-1700).

\section{Methods}

\section{Patient population}

Between January 2014 and July 2019, 1,561 patients underwent transfemoral TAVI for severe native aortic valve stenosis at the Klinik für Herz-und Kreislauferkrankungen, Deutsches Herzzentrum München, Munich, Germany. Of these, only patients treated with the Centera $(n=78)$ or the ACURATE neo SE-THV ( $\mathrm{n}=317)$ were considered for the current analysis, resulting in a final study population of 395 patients. Indication for TAVI was discussed by a multidisciplinary heart team and consensus was achieved regarding the minimal-invasive TAVI approach in all cases. The final decision on prosthesis type and size was left to the discretion of the treating physician considering anatomical features, calcification and the manufacturer's recommendations. All patients provided written informed consent prior to the procedure. Clinical data was collected by hospital chart reviews at the time of TAVI and entered in a dedicated database. Multi-Slice Computed Tomography (MS-CT) was available in 392/395 patients and measurements were performed as previously described (12) using 3MensioTM (Pie Medical, The Netherlands). Severity of calcification of the aortic valve was visually assessed and dichotomized in mild-moderate $v s$. severe. The study was conducted in accordance with the Declaration of Helsinki (as revised in 2013) and approved by the institutional board (5009/11).

\section{Device description}

The Centera SE-THV is a contour shaped, SE nitinol valve with intra-annular design and bovine pericardial leaflets, which gained CE mark in February 2018. In August 2019 Edwards Lifesciences decided to discontinue its production. Technical features have been described in detail elsewhere (10). In short, it is transfemorally delivered through an expandable 14 French E-sheath (Edwards Lifesciences, Irvine, CA, USA) with a steerable delivery catheter for precise positioning. The THV is pre-mounted on the delivery system and is released through a motorized handle, allowing recapturing and repositioning. Three different valve diameters $(23,26$ and $29 \mathrm{~mm})$ cover an annulus range from 18 to $26 \mathrm{~mm}$. Twenty-seven patients 
of this analysis were treated with the first iteration of the Centera SE-THV, which had a longer stiff end compared with the current THV.

The ACURATE neo SE-THV gained CE mark in 2014 and its technical features have been described elsewhere (9). Shortly, it features a supra-annular design with porcine pericardial leaflets mounted on a nitinol frame with pericardial sealing-skirt. The sizes "Small", "Medium" and "Large" cover an annulus range from 21 to $27 \mathrm{~mm}$. It is transfemorally delivered through an 18 to 20 French sheath. More recently a new expandable sheath, the iSLEEVE sheath (Boston Scientific, Marlborough, Massachusetts, USA) with a 14-French diameter became available.

\section{Definition of endpoints and follow-up}

All data and clinical endpoints of this analysis were prospectively collected and classified according to the VARC-2 definitions (13). The primary endpoint was the combined endpoint "Device success", including absence of procedural mortality, correct positioning of a single THV into the proper anatomic location, and intended performance of the THV (no prosthesis-patient mismatch, mean aortic valve gradient $<20 \mathrm{mmHg}$ or peak velocity $<3 \mathrm{~m} / \mathrm{s}$, with no moderate or severe valve regurgitation) and no need of conversion to sternotomy. Furthermore, the endpoint "procedural success", a composite of successful vascular access, delivery and deployment of the device and successful retrieval of the delivery system, was assessed.

During follow-up the combined endpoint "early safety at 30 days", which is a composite of all-cause mortality, all stroke, life-threatening bleeding and acute kidney injury (stage 2 or 3 or renal replacement therapy), coronary artery obstruction requiring intervention, major vascular complication and valve-related dysfunction requiring a repeated procedure was computed. For this endpoint, a time to first event analysis was performed and patients were censored after the first event. In order to establish clinical benefit from the procedure, New York Heart Association (NYHA) functional class was recorded prior to TAVI and at 30 days. Valve dysfunction was assessed by echocardiography at 30 days and included mean transvalvular transaortic gradient $\geq 20 \mathrm{mmHg}$, PVL II+ or effective orifice area (EOA) $\leq 0.9 \mathrm{~cm}^{2}$. Neurological assessment was performed by an independent neurologist and was based on clinical manifestations and neuroimaging and was adjudicated according to VARC-2 recommendations. Follow-up data were prospectively collected during routine ambulatory visits at the outpatients' clinic, by referring to the treating physician, hospital documentation or through telephone interview.

\section{Statistical analysis}

Continuous variables are expressed as mean with standard deviation or median with interquartile range. Event rates during follow-up were calculated as Kaplan-Meier estimates, $\mathrm{P}$ values for group comparison were generated using the log rank test. To investigate factors associated with the primary endpoint, a multivariable logistic regression model was computed adjusting for imbalances in baseline characteristics derived from univariate analysis. Factors were entered in the multivariable logistic regression model if they achieved significant $\mathrm{P}$ value $<0.05$ by univariate analysis (Online Resource Table S1). Choice of THV model was included independently of its $\mathrm{P}$ value in univariate analyses in order to assess its impact on the primary endpoint. To account for differences for the secondary endpoint, a Cox proportional hazards regression model was computed, adjusting for variables yielding a $\mathrm{P}$ value $<0.05$ in the univariate analysis (Online Resource Table S2).

A 2-sided $\mathrm{P}$ value of $<0.05$ was considered statistically significant for all analyses. IBM SPSS Statistics (Version 25, SPSS Inc., Chicago, Illinois, USA) and R (Version 3.3.2, The R Foundation, Vienna, Austria) were used for all analyses.

\section{Results}

\section{Patient population}

The mean age of the study population was $81.0 \pm 6.0$ years, $53.4 \%$ were female and the median EuroScore I was 13.5\% [8.0-21.0]. Baseline characteristics according to THV are displayed in Table 1. Despite a higher body mass index and a higher rate of diabetes mellitus in the ACURATE neo group, demographics, preoperative risk stratification and symptom severity were equally distributed. Furthermore, there were no differences in baseline echocardiography, ECG or anatomic features measured by MS-CT (Table 1).

\section{Procedural outcome and device success}

The small, medium and large ACURATE neo SE-THV were implanted in $30.9 \%, 38.2 \%$ and $30.9 \%$, respectively, whereas the Centera SE-THV 23, 26 and $29 \mathrm{~mm}$ were 
Table 1 Baseline characteristics

\begin{tabular}{|c|c|c|c|}
\hline Characteristics & Centera $(n=78)$ & ACURATE neo $(n=317)$ & $P$ value \\
\hline \multicolumn{4}{|l|}{ Clinical characteristics } \\
\hline Age (years) & $81.2 \pm 5.9$ & $80.9 \pm 6.1$ & 0.648 \\
\hline Female gender & $43(55.1)$ & $168(53.0)$ & 0.735 \\
\hline Body mass index $\left(\mathrm{kg} / \mathrm{m}^{2}\right)$ & $25.5 \pm 5.2$ & $26.6 \pm 4.5$ & 0.047 \\
\hline NYHA III/IV & $46(59.0)$ & $193(60.9)$ & 0.757 \\
\hline Chronic obstructive pulmonary disease & $12(15.4)$ & 39 (12.3) & 0.467 \\
\hline Diabetes mellitus & $11(14.1)$ & $83(26.2)$ & 0.025 \\
\hline Glomerular filtration rate (mL/min) & $55.1 \pm 19.4$ & $52.8 \pm 19.2$ & 0.332 \\
\hline Coronary artery disease & $67(85.9)$ & $271(85.5)$ & 0.927 \\
\hline Previous coronary artery bypass grafting & $9(11.5)$ & $37(11.7)$ & 0.974 \\
\hline \multicolumn{4}{|l|}{ Echocardiography } \\
\hline Left ventricular ejection fraction $<35 \%$ & $4(5.1)$ & $20(6.3)$ & 0.696 \\
\hline Pulmonary hypertension ${ }^{a}$ & 9 (11.5) & $27(8.5)$ & 0.406 \\
\hline \multicolumn{4}{|l|}{ ECG } \\
\hline Atrial fibrillation & $24(30.8)$ & $127(40.1)$ & 0.130 \\
\hline Right bundle branch block & $7(9.0)$ & $21(6.6)$ & 0.469 \\
\hline
\end{tabular}

Data are mean \pm standard deviation, median [interquartile range] or $\mathrm{n}(\%){ }^{\text {a }}$, pulmonary arterial pressure on echocardiography $\geq 60 \mathrm{mmHg} ;{ }^{\mathrm{b}}$, available for 392/395 patients; NYHA, New York Heart Association functional class.

deployed in $14.1 \%, 53.8 \%$ and $32.1 \%$, respectively. Procedural characteristics and outcome according to implanted THV are displayed in Table 2. Patients in both groups were predilated in $>98 \%$ of cases, while patients treated with the ACURATE neo SE-THV more often required post-dilatation $(60.6 \%$ vs. $48.7 \% ; \mathrm{P}=0.057)$, resulting in longer procedural time $(57.5 \pm 22.1 \mathrm{vs}$. $48.1 \pm 17.4 \mathrm{~min} ; \mathrm{P}<0.001)$ and fluoroscopy time $[12.8$ (10.4-16.3) vs. 10.9 (9.0-13.5) min; $\mathrm{P}<0.001]$. Procedural success was similar between the two groups $(98.4 \% v s$. 96.2\%; $\mathrm{P}=0.196$ ): for the ACURATE neo SE-THV, procedural failure was caused by annulus rupture in two cases and valve embolization in three cases. In two patients treated with the Centera SE-THV, the valve could not be deployed and had to be retrieved due to missing annulus alignment, while one case showed severe valve recoil even after post-dilatation, requiring deployment of a second THV.

There was no difference in the primary endpoint device success between the groups $(91.8 \%$ vs. $93.6 \%$; $\mathrm{P}=0.598)$. Failure to achieve the endpoint was driven by residual PVL II+ in most cases, which was numerically higher 
Table 2 Procedural characteristics and in-hospital complications

\begin{tabular}{|c|c|c|c|}
\hline Characteristics & Centera $(n=78)$ & ACURATE neo $(n=317)$ & $P$ value \\
\hline Conscious sedation & $73(93.6)$ & $123(38.8)$ & $<0.001$ \\
\hline Pre-dilatation & $77(98.7)$ & $317(100.0)$ & 0.197 \\
\hline Post-dilatation & $38(48.7)$ & $192(60.6)$ & 0.057 \\
\hline Contrast (mL) & $140.6 \pm 39.7$ & $141.5 \pm 47.3$ & 0.886 \\
\hline Fluoroscopy time (min) & $10.9[9.0-13.5]$ & 12.8 [10.4-16.3] & $<0.001$ \\
\hline Oversizing by area (\%) & $32.7 \pm 8.5$ & $48.6 \pm 14.3$ & $<0.001$ \\
\hline Procedural success ${ }^{a}$ & 75 (96.2) & $312(98.4)$ & 0.196 \\
\hline \multicolumn{4}{|l|}{ In-hospital complications } \\
\hline All-stroke & $4(5.1)$ & $4(1.3)$ & 0.052 \\
\hline Disabling stroke & $2(2.6)$ & $2(0.6)$ & 0.176 \\
\hline Non-disabling stroke & $2(2.6)$ & $2(0.6)$ & 0.176 \\
\hline Major vascular complication & $8(10.3)$ & $54(17.0)$ & 0.140 \\
\hline Life-threatening bleeding & $3(3.8)$ & $14(4.4)$ & 0.999 \\
\hline Renal failure (AKIN 2/3, including dialysis) & $0(0)$ & $4(1.3)$ & 0.999 \\
\hline New permanent pacemaker implantation ${ }^{\mathrm{b}}$ & $5(7.1)$ & $24(8.4)$ & 0.726 \\
\hline
\end{tabular}

Data are mean \pm standard deviation, median [interquartile range] or $\mathrm{n}(\%) .{ }^{a}$, composite of successful vascular access, delivery and deployment of the device, successful retrieval of the delivery system; ${ }^{b}$, for patients without previous pacemaker. AKIN, acute kidney injury network.

Table 3 Device success and individual components

\begin{tabular}{|c|c|c|c|}
\hline Characteristics & Centera $(n=78)$ & ACURATE neo $(n=317)$ & $P$ value \\
\hline Intended performance ${ }^{b}$ & 75 (96.2) & $296(93.4)$ & 0.439 \\
\hline Paravalvular leakage $\geq I^{\circ}$ & $1(1.3)$ & $15(4.7)$ & 0.214 \\
\hline Elevated gradients $\geq 20 \mathrm{mmHg}$ & $0(0)$ & $6(1.9)$ & 0.603 \\
\hline Conversion to sternotomy & $1(1.3)$ & $2(0.6)$ & 0.484 \\
\hline Multiple valves & $3(3.8)$ & $6(1.9)$ & 0.389 \\
\hline Procedural death & $0(0)$ & $1(0.3)$ & 0.999 \\
\hline
\end{tabular}

${ }^{a}$, multiple events possible; ${ }^{b}$, no prosthesis mismatch, mean aortic valve gradient $<20 \mathrm{mmHg}$, or peak velocity $<3 \mathrm{~m} / \mathrm{s}$, without moderate or severe prosthetic valve aortic regurgitation of the first implanted prosthesis. 


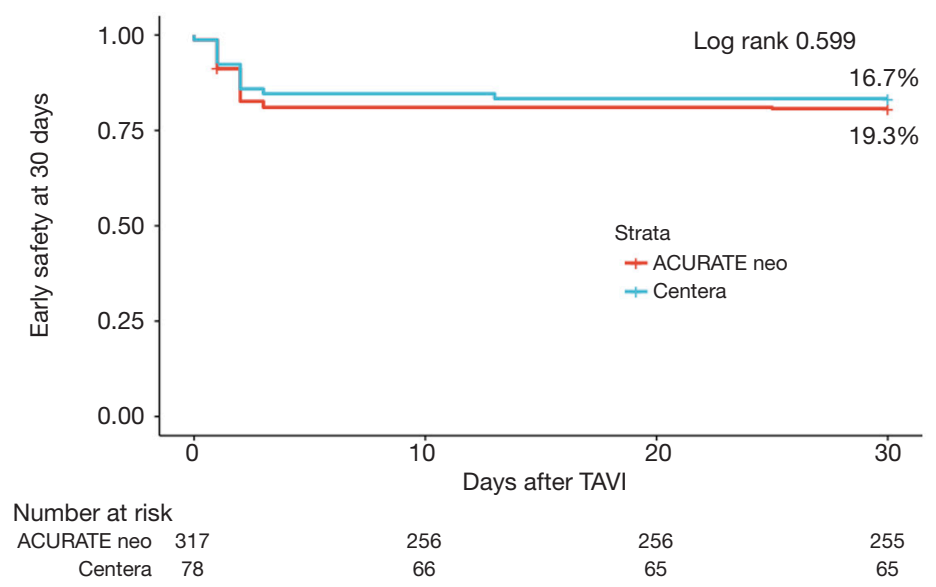

Figure 1 Kaplan-Meier survival curves for the composite endpoint "early safety at 30 days".

in the ACURATE neo group ( $4.7 \%$ vs. $1.3 \% ; \mathrm{P}=0.214$ ). Table 3 shows the individual components of this VARC-2 endpoint. By multivariate regression analysis, there was no association between valve type and device success [odds ratio, $1.410 ; 95 \%$ confidence interval (CI): 0.518-3.840; $\mathrm{P}=0.502]$. Online Resource Figure $\mathrm{S} 1$ shows that there is no significant learning curve through tertiles of consecutively treated patients for both THVs.

\section{In-hospital outcome}

In-hospital complications were similar among the two groups, however there was a non-significant trend towards higher stroke rates in patients treated with the Centera SE-THV (5.1\% vs. $1.3 \%$; $\mathrm{P}=0.052)$. Patients treated with the ACURATE neo SE-THV had numerically higher rates of major vascular complications $(17.0 \%$ vs. $10.3 \%$; $\mathrm{P}=0.140$ ). However, when considering patients treated with ACURATE neo SE-THV with use of a 14-French sheath rather than larger sheaths there was a reduction from $17.6 \%$ to $15.3 \%$ of vascular complications.

\section{0-day result and early safety composite endpoint}

Clinical follow-up was complete for all patients $(n=395)$. From discharge to 30 days no patient died, resulting in an all-cause mortality at 30 days of $0.2 \%(1 / 365)$. Figure 1 shows no significant difference in the composite early safety endpoint at 30 days between the two groups (ACURATE neo: $19.3 \%$ vs. Centera THV: $16.7 \% ; \mathrm{P}=0.599)$. Event rates at 30 days according to implanted THV are depicted in Table 4. In a Cox proportional hazards regression model, female gender, left and right bundle branch block were independent predictors of the early safety endpoint at 30 days, while the deployed THV showed no significant association (Online Resource Table S3). Online Resource Figure S2 shows that there was no significant learning curve through tertiles of consecutively treated patients for both THVs.

Except for stroke rates, which were significantly lower in the ACURATE neo compared to the Centera group (1.6\% vs. $6.4 \% ; \mathrm{P}=0.015)$, there were no differences between the THVs.

Figure 2 pictures the distribution across NYHA classes prior to procedure and at 30 days after TAVI according to THV: for both valves $>92 \%$ of patients were in NYHA class I or II at 30 days ( $92.3 \%$ vs. 94.7\%; $\mathrm{P}=0.463)$.

At 30 days, echocardiographic evaluation was available for $92.7 \%$ of patients treated with the ACURATE neo and for $94.9 \%$ of patients treated with the Centera SE-THV. Mean transvalvular gradient after procedure was low for both valves showing no significant difference and remained stable at 30 days (Figure 3).

\section{Discussion}

The present study compared the procedural and 30 days outcome of two contemporary SE-THVs. The main findings can be summarized as follows: firstly, both THV showed excellent procedural outcome with comparable rates of device success; the ACURATE neo SE-THV showed a non-significant trend of higher rates of residual PVL II+. Secondly, symptomatic benefit was high with these devices, with comparable rates of the early safety endpoint at 30 days. 
Table 4 Outcome at 30 days with Kaplan-Meier estimates

\begin{tabular}{|c|c|c|c|}
\hline Outcome & Centera $(n=78)$ & ACURATE neo $(n=317)$ & $P$ value \\
\hline All-cause mortality 30 days & $0(0)$ & $1(0.3)$ & 0.620 \\
\hline All stroke (disabling, non-disabling) & $5(6.4)$ & $5(1.6)$ & 0.015 \\
\hline Coronary artery obstruction requiring intervention & $0(0)$ & $1(0.3)$ & 0.620 \\
\hline Life-threatening bleeding & $4(5.1)$ & $14(4.4)$ & 0.797 \\
\hline Acute kidney injury (AKIN 2/3, including renal replacement) & $0(0)$ & $4(1.3)$ & 0.319 \\
\hline Valve-related dysfunction requiring repeat procedure & $0(0)$ & $0(0)$ & - \\
\hline New permanent pacemaker implantation ${ }^{\mathrm{b}}$ & $5(7.1)$ & $29(10.2)$ & 0.438 \\
\hline
\end{tabular}

a , multiple events possible; counting only first event; ${ }^{b}$, for patients without previous pacemaker. AKIN, acute kidney injury network; BAV, balloon aortic valvuloplasty; SAVR, surgical aortic valve replacement; TAVI, transcatheter aortic valve implantation.

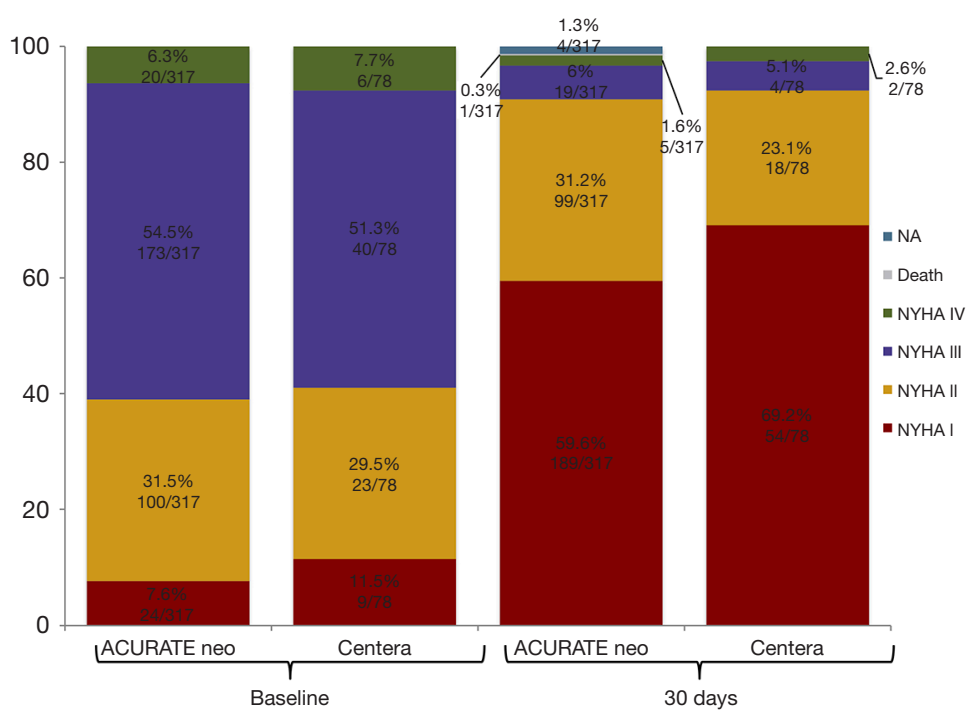

Figure 2 NYHA Functional class at baseline and at 30 days after procedure according to the implanted THV. THV, transcatheter heart valves.

Noteworthy, the Centera SE-THV was associated with significantly higher stroke rates at 30 days.

\section{Procedural outcome and device success}

The composite endpoint device success was proposed by VARC to ensure a measurement of short-term procedural outcome and THV function. For the ACURATE neo SE-THV reported rates of device success range from $89-98 \%(8,9,14)$, while for the Centera SE-THV data is limited to the Centera EU study, which reported device success in $96 \%$ with a residual PVL II+ rate of $0.6 \%(10)$. Consistent with other reports $(8,9,14)$, we found a nonsignificant trend of higher residual PVLII+ rates of $4.7 \%$ in the ACURATE neo compared to $1.3 \%$ with the Centera SE-THV. This finding may be explained by the relatively lower radial force of the ACURATE neo SETHV, and the novel contoured shape of the Centera SETHV resulting in improved sealing of the aortic annulus. The low PVLII+ rates found with the Centera SE-THV compares favorably to other contemporary SE-THV such as the Evolut PRO (Medtronic, Minneapolis, Minnesota, 


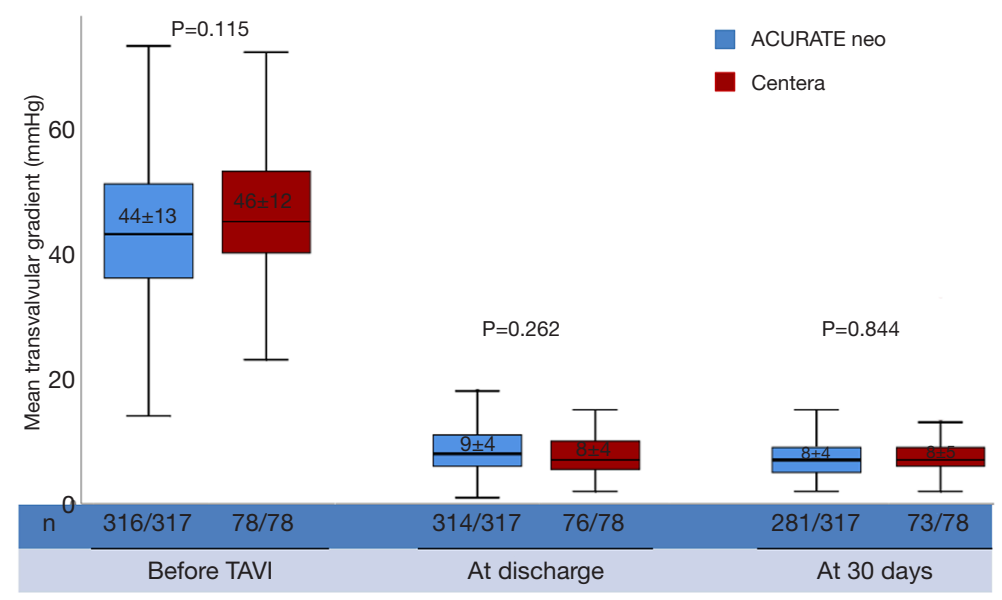

Figure 3 Mean transvalvular gradients according to THV before TAVI, at discharge and at 30 days. THV, transcatheter heart valves; TAVI, transcatheter aortic valve implantation.

USA), where PVLII+ rates between 0-5.7\% were reported $(14,15)$, and the Portico THV (Abbott, Abbott Park, Illinois, USA) with PVLII+ rates between 2.6-8.2\% $(16,17)$. Considering the adverse impact of residual PVL on outcome, further improvement should be paramount to reduce this hurdle with the ACURATE neo SE-THV. In fact, a new iteration of this THV, the ACURATE neo 2.0, featuring an additional sealing skirt is currently in CE mark studies. The possibility of recapturing and repositioning may have also contributed to mitigate the PVL rates with the Centera SE-THV, especially in a subset of patients with severely calcified aortic annuli. However, results with the repositionable Evolut Pro show PVL rates comparable with non-repositionable THVs. Thus, possible advantages of repositioning to achieve lower PVL rates should be weighed against potential downsides through manipulation in calcified anatomies, such as longer procedural times and increased risk of stroke.

Besides PVL, hemodynamic performance of THV is important and increased transvalvular gradients bear a potentially detrimental impact on long-term durability. Despite its intra-annular design, the Centera THVs showed low, single digit transvalvular gradients at discharge and at 30 days, comparable to the ACURATE neo and similar to those described with other latest generation SE THVs $(18,19)$. A possible explanation of the favorable hemodynamic performance of the Centera valve may be related to its geometric design, which mimics the natural aortic root anatomy providing adaptive sealing of the natural annulus, with reduced tissue interference resulting in physiological flow and low transvalvular gradients.

\section{Early safety at 30 days}

The early safety endpoint at 30 days summarizes important measures of complications and mortality and was proposed for the assessment of short-term patient safety after TAVI. In the present analysis we found comparable cumulative rates for both analyzed THVs, namely $19.3 \%$ for the ACURATE neo and $16.7 \%$ for the Centera THV. Similar rates ranging from $8.6 \%$ to $17.9 \%(8,9,14,20)$ can be found for the ACURATE neo SE-THV as well as for other contemporary SE platforms, between 11-15\% for the Evolut PRO $(14,15)$, $14-22 \%$ for the Portico platform $(18,21)$. Whereas, this endpoint has not yet been reported for the Centera SE-THV. All-cause mortality was very low in the entire population and while there was no difference in most clinical endpoints at 30 days, two findings are worthy of discussion.

Firstly, patients treated with the Centera SE-THV showed significantly higher stroke rates at 30 days compared to patients treated with the ACURATE neo SE-THV. Recently, an analysis including more than 100,000 TAVI patients over 5 -year reported a stroke rate of $2.3 \%$ at 30 days and interestingly, there was no difference over the inclusion period despite the evolution of THV technology (22). The ACURATE neo compares favorably to these data with reports of all stroke of $2 \%(8,14,23)$. Comparably stroke rates of $1.7-2.8 \%$ were found with the Evolut PRO $(14,15,24)$ and rates ranging from $1.6 \%$ to $3 \%$ for the Portico THV $(18,25)$. Importantly, the stroke rates of the current analysis have to be interpreted with caution: the sample size of the current analysis is limited resulting in relative inflation of rare complications such as stroke and others. In the current analysis no cerebral protection devices 
were used, which might have mitigated cerebral embolic risk. A possible explanation for the higher stroke rate in Centera SE-THV may be an increased interaction of the steerable distal part of the Centera delivery catheter in the aortic arch and ascending aorta, as well as increased manipulation of the aortic valve apparatus during recapturing and repositioning. Importantly, there was no difference in stroke rates between the first iteration of the Centera SE-THV and the second (data not shown). Since additional studies with increased sample size are unlikely to be performed with the Centera SE-THV, the findings of the current study may be considered hypothesis-generating for future SE valve design, especially for valves of intra-annular design.

Vascular complications were numerically higher in patients treated with the ACURATE neo SE-THV, which may be explained by the relatively larger sheath size (18-20 French) used when the ACURATE neo SE-THV was introduced into market. With introduction of lower profile sheaths, this specific complication is likely to decrease. Indeed, Kim et al. showed a significant reduction of vascular complication when using only the expandable mesh component of the transGlide introducer system with an inner diameter to 13 French compared to larger sheath sizes (26).

\section{Limitations}

To our knowledge this is the first analysis comparing the ACURATE neo SE-THV and Centera SE-THV. Albeit including a 395 patients strong, real-world population treated at a high-volume center and presenting complete data, including 30 days follow-up, this analysis carries some limitations: first of-all, this is an observational study with self-adjudication of events, lacking a central core-laboratory. Further, despite a homogenous patient population presenting few baseline differences, which were accounted for through statistical means, selection bias cannot be ruled out. Because of the small sample size, outcomes should be validated in larger populations in order to reduce possible bias.

\section{Conclusions}

In conclusion, the low mortality rates and low need for new PPI, as well as the favorable hemodynamics make both THV appealing with respect to the extension of TAVI towards a younger and low-risk population. Beside a longer follow-up for both THV, which is needed to retrieve information on durability and long-term outcome, further research is warranted to assess the finding of higher stroke rates with the intra-annular, repositionable Centera SETHV and its implications for this design.

\section{Acknowledgments}

Funding: None.

\section{Footnote}

Reporting Checklist: The authors have completed the STROBE reporting checklist. Available at http://dx.doi. org/10.21037/jtd-20-1700

Data Sharing Statement: Available at http://dx.doi. org/10.21037/jtd-20-1700

Conflicts of Interest: All authors have completed the ICMJE uniform disclosure form (available at http://dx.doi. org/10.21037/jtd-20-1700). AMK reports that he is a proctor and consultant for Edwards Lifesciences. The other authors have no conflicts of interest to declare.

Ethical Statement: The authors are accountable for all aspects of the work in ensuring that questions related to the accuracy or integrity of any part of the work are appropriately investigated and resolved. The study was conducted in accordance with the Declaration of Helsinki (as revised in 2013) and approved by the institutional board (5009/11). All patients gave their informed consent prior to the inclusion in the study.

Open Access Statement: This is an Open Access article distributed in accordance with the Creative Commons Attribution-NonCommercial-NoDerivs 4.0 International License (CC BY-NC-ND 4.0), which permits the noncommercial replication and distribution of the article with the strict proviso that no changes or edits are made and the original work is properly cited (including links to both the formal publication through the relevant DOI and the license). See: https://creativecommons.org/licenses/by-nc-nd/4.0/.

\section{References}

1. Mack MJ, Leon MB, Thourani VH, et al. Transcatheter Aortic-Valve Replacement with a Balloon-Expandable Valve in Low-Risk Patients. N Engl J Med 2019;380:1695-705. 
2. Popma JJ, Deeb GM, Yakubov SJ, et al. Transcatheter Aortic-Valve Replacement with a Self-Expanding Valve in Low-Risk Patients. N Engl J Med 2019;380:1706-15.

3. Holmes DR Jr, Brennan JM, Rumsfeld JS, et al. Clinical outcomes at 1 year following transcatheter aortic valve replacement. JAMA 2015;313:1019-28.

4. Leon MB, Smith CR, Mack MJ, et al. Transcatheter or Surgical Aortic-Valve Replacement in Intermediate-Risk Patients. N Engl J Med 2016;374:1609-20.

5. Abdel-Wahab M, Mehilli J, Frerker C, et al. Comparison of balloon-expandable vs self-expandable valves in patients undergoing transcatheter aortic valve replacement: the CHOICE randomized clinical trial. JAMA 2014;311:1503-14.

6. Toggweiler S, Nissen H, Mogensen B, et al. Very low pacemaker rate following ACURATE neo transcatheter heart valve implantation. EuroIntervention 2017;13:1273-80.

7. Pellegrini C, Husser O, Kim WK, et al. Predictors of Need for Permanent Pacemaker Implantation and Conduction Abnormalities With a Novel Self-expanding Transcatheter Heart Valve. Rev Esp Cardiol (Engl Ed) 2019;72:145-53.

8. Husser O, Kim WK, Pellegrini C, et al. Multicenter Comparison of Novel Self-Expanding Versus BalloonExpandable Transcatheter Heart Valves. JACC Cardiovasc Interv 2017;10:2078-87.

9. Möllmann H, Hengstenberg C, Hilker M, et al. Realworld experience using the ACURATE neo prosthesis: 30day outcomes of 1,000 patients enrolled in the SAVI TF registry. EuroIntervention 2018;13:e1764-70.

10. Reichenspurner H, Schaefer A, Schäfer U, et al. SelfExpanding Transcatheter Aortic Valve System for Symptomatic High-Risk Patients With Severe Aortic Stenosis. J Am Coll Cardiol 2017;70:3127-36.

11. Hahn RT, Leipsic J, Douglas PS, et al. Comprehensive Echocardiographic Assessment of Normal Transcatheter Valve Function. JACC Cardiovasc Imaging 2019;12:25-34.

12. Pellegrini C, Kim WK, Holzamer A, et al. Multicenter Evaluation of Prosthesis Oversizing of the SAPIEN 3 Transcatheter Heart Valve. Impact on Device Failure and New Pacemaker Implantations. Rev Esp Cardiol (Engl Ed) 2019;72:641-8.

13. Kappetein AP, Head SJ, Généreux P, et al. Updated standardized endpoint definitions for transcatheter aortic valve implantation: the Valve Academic Research Consortium-2 consensus document (VARC-2). Eur J Cardiothorac Surg 2012;42:S45-60.
14. Pagnesi M, Kim WK, Conradi L, et al. Transcatheter Aortic Valve Replacement With Next-Generation SelfExpanding Devices: A Multicenter, Retrospective, Propensity-Matched Comparison of Evolut PRO Versus Acurate neo Transcatheter Heart Valves. JACC Cardiovasc Interv 2019;12:433-43.

15. Forrest JK, Mangi AA, Popma JJ, et al. Early Outcomes With the Evolut PRO Repositionable Self-Expanding Transcatheter Aortic Valve With Pericardial Wrap. JACC Cardiovasc Interv 2018;11:160-8.

16. Søndergaard L, Rodés-Cabau J, Hans-Peter Linke A, et al. Transcatheter Aortic Valve Replacement With a Repositionable Self-Expanding Prosthesis: The PORTICO-I Trial 1-Year Outcomes. J Am Coll Cardiol 2018;72:2859-67.

17. Mas-Peiro S, Seppelt PC, Weiler H, et al. A Direct Comparison of Self-Expandable Portico Versus BalloonExpandable Sapien 3 Devices for Transcatheter Aortic Valve Replacement: A Case-Matched Cohort Study. J Invasive Cardiol 2019;31:E199-E204.

18. Makkar RR, Cheng W, Waksman R, et al. Self-expanding intra-annular versus commercially available transcatheter heart valves in high and extreme risk patients with severe aortic stenosis (PORTICO IDE): a randomised, controlled, non-inferiority trial. Lancet 2020;396:669-83.

19. Giordano A, Corcione N, Ferraro P, et al. Comparative one-month safety and effectiveness of five leading new-generation devices for transcatheter aortic valve implantation. Sci Rep 2019;9:17098.

20. Pellegrini C, Rheude T, Trenkwalder T, et al. One-year clinical outcome with a novel self-expanding transcatheter heart valve. Catheter Cardiovasc Interv 2019;94:783-92.

21. Perlman GY, Cheung A, Dumont E, et al. Transcatheter aortic valve replacement with the Portico valve: one-year results of the early Canadian experience. EuroIntervention 2017;12:1653-9.

22. Huded CP, Tuzcu EM, Krishnaswamy A, et al. Association Between Transcatheter Aortic Valve Replacement and Early Postprocedural Stroke. JAMA 2019;321:2306-15.

23. Lanz J, Kim WK, Walther T, et al. Safety and efficacy of a self-expanding versus a balloon-expandable bioprosthesis for transcatheter aortic valve replacement in patients with symptomatic severe aortic stenosis: a randomised noninferiority trial. Lancet 2019;394:1619-28.

24. Manoharan G, Van Mieghem NM, Windecker S, et al. 1-Year Outcomes With the Evolut R Self-Expanding Transcatheter Aortic Valve. JACC Cardiovasc Interv 2018;11:2326-34. 
25. Maisano F, Worthley S, Rodés-Cabau J, et al. Early commercial experience from transcatheter aortic valve implantation using the Portico ${ }^{\mathrm{TM}}$ bioprosthetic valve: $30-$ day outcomes in the multicentre PORTICO-1 study. EuroIntervention 2018;14:886-93.

Cite this article as: Pellegrini C, Rheude T, Michel J, AlvarezCovarrubias HA, Wünsch S, Mayr NP, Xhepa E, Kastrati A, Schunkert H, Joner M, Kasel M. Comparison of latest generation supra-annular and intra-annular self-expanding transcatheter heart valves. J Thorac Dis 2020;12(11):6769-6779. doi: $10.21037 /$ jtd-20-1700
26. Kim WK, Brinkert M, Mangner N, et al. Transfemoral implantation of the ACURATE neo prosthesis using a low-profile expandable introducer system: A multicenter registry. Int J Cardiol 2019;281:76-81. 